\title{
Guardianes del progreso. Los periódicos afroporteños entre 1873 y 1882
}

Lea Geler ${ }^{l}$

Departamento de Historia de América, Universidad de Barcelona

El trabajo se centra en la prensa afroporteña en el período comprendido entre 1873 y 1882, estudiándola como un conjunto particular dentro del proceso general de consolidación del Estado-nación argentino. Indagamos en su funcionamiento, circulación y formas y, especialmente, en la relación entre los directores y redactores de los periódicos entre sí y con sus lectores. Sostendremos que, a través de la acción de los periodistas y con las herramientas poderosas que daba la prensa, se promovieron las ideas de "progreso" en una comunidad afroporteña que, asimismo, se vio progresivamente controlada por sus intelectuales.

PALABRAS CLAVE: afroporteños, 1873-1882, periódicos, control social.

This paper will focus on the Afro-Argentinian press of Buenos Aires, between 1873 and 1882, as a particular phenomenon inscribed in the state building process of Argentine. We will analyse the ways in which these newspapers circulated and the relationship they developed with their readers and between each other. We will also see that, through the powerful tools given by the press and the actions of the journalists, the Afro-descendant community of Buenos Aires was progressively "watched", but permeated altogether with the ideas of "civilization and progress" that their journalists felt this community lacked.

KEYwoRDS: Afro-Argentinians of Buenos Aires, 1873-1882, newspapers, social control.

\section{Introducción}

Durante la segunda mitad del siglo XIX, y siguiendo una tendencia que afectaba a los países europeos y americanos, la Argentina se vio inmersa en una corriente ascendente y aparentemente imparable de profusión de

1 Con el apoyo del DURSI (Generalitat de Catalunya). Este trabajo forma parte de la tesis doctoral en curso sobre la población afroporteña y se inscribe en el proyecto de investigación del Ministerio de Educación y Ciencia de España (HUM2006-12351), coordinado por la doctora Pilar García Jordán. Agradezco sus comentarios a los evaluadores anónimos de la revista. 
publicaciones escritas, en la que los periódicos fueron protagonistas. Leer o sostener periódicos se transformaron en maneras fundamentales de participación en la vida social, permitiendo la creación de una imaginación nacional $^{2}$ al involucrar a los lectores en los eventos de su país - o del país al que hacía poco se había arribado- fomentando la intervención y la opinión individual y colectiva. ${ }^{3}$ Como ha señalado Sábato, ${ }^{4}$ diarios, periódicos y revistas eran herramientas primordiales de comunicación, vehículos de cohesión social y de acción sobre lo cotidiano que influían en una opinión pública que simultáneamente generaban y llegaban, en ocasiones, a afectar la toma de decisiones a nivel político. Esto era así porque lograban mediar entre la sociedad civil y el Estado, constituyéndose como un "actor político colectivo". ${ }^{5}$ Y era el mismo Estado el que defendía la libertad de prensa, porque se consideraba que el sistema republicano de gobierno, el grado de civilización de los pueblos y los valores liberales estaban ligados con la expresión de las ideas a través de este medio.

Dentro de este proceso se puede apreciar el desarrollo de una prensa de carácter popular, ${ }^{6}$ parte importante de la cual era publicada por y para la población afrodescendiente de la ciudad, a la que denominaremos genéricamente "prensa afroporteña". Como señalara Chamosa, ${ }^{7}$ estas publicaciones afrodescendientes circulaban por un ámbito localizado y relativamente pequeño y, en general, de forma paralela a la esfera pública por la que discurrían los periódicos nacionales o locales pertenecientes a los grupos hegemónicos (que incluía a los afroporteños entre sus lectores) y a periódicos de otros grupos subalternos. Conformaban así lo que hemos llamado en otra parte, siguiendo la propuesta de Nancy Fraser, "contra esfera pública

2 Anderson, Benedict: Comunidades imaginadas. Reflexiones sobre el origen y la difusión del nacionalismo, Fondo de Cultura Económica, México, 1993.

3 Este tema es profundamente abordado por Sábato, Hilda: La política en las calles. Entre el voto y la movilización. Buenos Aires, 1862-1880, Sudamericana, Buenos Aires, 1998.

4 Sábato: La política...

5 Díaz, César Luis: "Tras las huellas de un periodismo «desaparecido»", Oficios Terrestres. Publicación de la Facultad de Periodismo y Comunicación Social de la Universidad Nacional de La Plata, año X, n. ${ }^{\circ}$ 15/16, La Plata, 2004, págs. 62-69.

6 González Bernaldo de Quirós detectaba este fenómeno durante el gobierno rosista de las primeras décadas del siglo XIX. González Bernaldo de Quirós, Pilar: Civilidad y política en los orígenes de la Nación Argentina. Las sociabilidades en Buenos Aires, 1829-1862, Fondo de Cultura Económica, Buenos Aires, 2001.

7 Chamosa, Oscar: Asociaciones africanas de Buenos Aires. 1823-1880. Introducción a la sociabilidad de una comunidad marginada. Tesis de Licenciatura en Historia, Universidad Nacional de Luján, 1995. 
subalterna" afroporteña. ${ }^{8}$ Esa esfera pública subalterna, de potencial poder contrahegemónico pero también espacio de recreación identitaria, ofrecía en momentos puntuales la posibilidad de visibilización en la esfera pública burguesa y asimismo podía llegar a mediar con el Estado frente a demandas concretas que pudiera tener la comunidad. ${ }^{9}$

En este trabajo se analiza, durante el período entre 1873 y 1882, la prensa afroporteña como un conjunto con una dinámica particular dentro del proceso histórico hacia la consolidación del Estado nacional. Utilizamos para ello los periódicos afroporteños La Broma, La Igualdad, La Perla, La Juventud, El Unionista, La Luz y El Aspirante..$^{10}$ A través del análisis de estas siete publicaciones proponemos que los periódicos afroporteños - con una determinada acción de sus periodistas - tuvieron un papel destacado en el disciplinamiento de la comunidad y en la introducción de determinados ideales de civilización y progreso que el Estado y los grupos hegemónicos sostenían. Así, en primer lugar, estudiaremos los objetivos que los propios periódicos explicitaban tener para salir a la luz pública. En segundo lugar, indagamos en las formas que adoptaban y las maneras en que circulaban los periódicos. En tercer lugar, se analizan los diversos posicionamientos de sus directores y redactores. A continuación, abordamos la relación que estas publicaciones establecían con sus lectores y, por último, en quinto lugar, el gran poder de control y coerción social que detentaban, y ejercían, quienes estaban a cargo de ellos.

\section{En busca del cambio y del progreso}

En la ciudad de Buenos Aires del período que se estudia, las ideas sobre la importancia de la opinión pública, de la prensa y de la relación

8 Fraser, Nancy: "Rethinking the Public Sphere: A Contribution to the Critique of Actually Existing Democracy", en: Calhoun, C. (ed.): Habermas and the Public Sphere, The MIT Press, Cambridge, 1992, págs. 109-142 y Geler, Lea: "La sociedad «de color» se pone de pie. Resistencia, visibilidad y esfera pública en la comunidad afrodescendiente de Buenos Aires, 1880", en: Dalla Corte, G.; García Jordán, P., et al. (coords.): Homogeneidad, diferencia y exclusión en América Latina, Publicacions de la Universitat de Barcelona, Barcelona, 2006, págs 141-153.

9 En otra ocasión estudiamos un caso de discriminación en un local bailable, ocurrido en 1880 , en el que la movilización afroporteña guiada desde la acción de la prensa comunitaria y apoyada por los periódicos La Tribuna y El Porteño forzó a la municipalidad y a la policía a extender una orden antidiscriminatoria a favor de la libre entrada de los afroporteños a los salones. Geler: "La sociedad...". Argentina.

10 Estas publicaciones se encuentran en la Sala del Tesoro de la Biblioteca Nacional 
entre ésta y el progreso y la civilización eran fundamentales, y los periodistas afroporteños las compartían cabalmente. De hecho, se exponía de forma continuada que los periódicos eran herramientas de cambio que debían ser utilizadas por el bien de la comunidad. Y donde mejor quedaba plasmada la idea de la relación entre prensa e ilustración, cambio y progreso era en los propios objetivos que se fijaban los periódicos.

El primer número de La Juventud, por ejemplo, estaba encabezado por un artículo donde se detallaban los objetivos y razones que tenían sus fundadores para publicar este periódico. En él se proclamaba como un instrumento sin divisas políticas, destinado a promover la unión de la comunidad y el abandono de hábitos que supuestamente la desmembraban, para ubicarla en la senda de la verdadera libertad y progreso:

"Contribuyamos de una vez por todas para que nuestra unión social sea un hecho, y habrá llegado el momento en que deba hacerse práctica nuestra deseada libertad política (...). Nace pues La Juventud, (...) sin más divisa que la del bien común, y sus columnas las ponemos a disposición de todas las personas sin distinción de sexos".

El ofrecimiento de sus páginas a toda la comunidad $-\mathrm{y}$ a ambos sexos - es importante, ya que estos periódicos se proponían como parte activa de la vida comunitaria, como lugar de discusión pública, como espacio de unión y como motor de cambio. Unos años más tarde, La Juventud volvía a explicitar el poder que para sus redactores tenían los periódicos:

"El periódico es un gran medio para introducir remodificaciones profundas; fue él quien pudo vencer a la Santa Alianza, con igual facilidad a la que tuvo Franklin para emancipar la América...". ${ }^{2}$

Los objetivos de La Juventud no diferían mucho de los propuestos por La Broma, que aparecía unos meses más tarde. Aunque esta última se posicionaba en principio casi exclusivamente como relatora de la crónica social, ${ }^{13}$ posteriormente señalaba:

"Parece que va despertando nuestra sociedad del letargo en que yacía (...) Esto nos demuestra que nuestro trabajo no es estéril (...) Hemos de sostener La Broma cueste lo que cueste, porque sabemos que ella es necesaria para batallar en los futuros días

11 La Juventud, "Nuestra misión", 1 de enero de 1876.

12 Ibídem, "Las habladurías sirven al desorden...", 30 de septiembre de 1878.

13 La Broma, 20 de septiembre de 1877. 
de la lucha ardiente de la inteligencia contra la ignorancia (...) Cuenta con esforzados paladines y militan en sus filas hombres de corazón y voluntad de hierro". ${ }^{14}$

El lenguaje tan ligado al ámbito de la lucha política que utilizaba $L a$ Broma no debe pasar desapercibido. Para estos redactores, la política que decían rechazar constituía una parte muy importante de su vida cotidiana. ${ }^{15}$ El interés de La Broma en "batallar contra la ignorancia" y hacer "despertar del letargo" a la comunidad, la situaba como forjadora de cambios comunitarios, a la vez que como elemento unificador y posibilitador de la comunicación intragrupal —relatando los sucesos que acontecían en la comunidad, por ejemplo-, ayudando a crear "imaginación" comunitaria. ${ }^{16}$ $\mathrm{Al}$ igual que La Juventud, se proponía como un periódico no político, independiente y redactado para promocionar el bien y el progreso de toda la comunidad, con sus páginas disponibles para quienes quisieran colaborar en ellas.

Cuando en mayo de 1878 aparecía el primer número de $L a L u z$, se establecía el carácter independiente del periódico, y más adelante se exponía:

"El que vive sumido en la ignorancia ¿acaso podrá llamarse racional e inteligente, hombre ni ciudadano? (...) Es indispensable hacer que desaparezca esta rémora vergonzosa, con el estímulo literario, con la mayor propagación posible de las bibliotecas y con las publicaciones de obras populares; moralizando la prensa; perfeccionando a la par y corrigiendo en sus defectos orgánicos el arte tipográfico. Preciso será pues, que la prensa se haga cargo de vulgarizar hasta los arcanos más recónditos de la ciencia, dando a cada uno y a todos aquel alimento intelectual que pueda serle útil en la vida práctica". ${ }^{17}$

Vemos claramente que para el redactor de $L a L u z$ el periódico también se constituía como un elemento de cambio fundamental, necesario para la comunidad afroporteña debido a su "ignorancia". En la misma línea, declaraba que " $L a L u z$ viene al vasto escenario de la prensa con el deseo de ilustrarse, y si es posible ilustrar a nuestros hermanos" ${ }^{18} \mathrm{y}$, como en los casos anteriores, ofrecía sus columnas:

14 Ibídem, "Nuestra misión", 21 de enero de 1878, cursivas en el original.

15 Geler, Lea: "«Aquí... se habla de política». La participación de los afroporteños en las elecciones presidenciales de 1874", Revista de Indias, vol. LXVII, n. ${ }^{\circ}$ 240, Madrid, 2007, págs. 459-484.

16 Anderson: Comunidades...

17 La Luz, "Una palabra al público", 3 de mayo de 1878, cursivas en el original.

18 Ibídem, "A la prensa", 3 de mayo de 1878, cursivas en el original. 
“... para tratar de los intereses de nuestra comunidad y para prepararnos en el provenir que nos espera. A nuestra redacción pueden enviarse las producciones literarias y cualquier trabajo que tienda al adelanto de nuestra clase (...) Cualquier escrito que esté conteste con las ideas de la Redacción será acogido con la benevolencia que merezca, pues nos dará también una idea para apreciar el desenvolvimiento de nuestro progreso. Ánimo, ánimo; no os dejéis matar por la apatía y nuestros esfuerzos y los vuestros coronarán la grandiosa obra de civilización que emprendemos con fe". ${ }^{19}$

Como podemos observar, el poder de la prensa para la educación y el correspondiente cambio social que ésta traería aparejado eran ideas muy arraigadas que servirían para propagar "los principios cosmopolitas de unión, igualdad y fraternidad". ${ }^{20}$

Casi calcado de los anteriores, el programa que aparecía con motivo de la refundación de La Perla en junio de 1879 decía:

"La Perla, como hemos dicho tantas veces, es y será el órgano genuino entre nosotros, y ella hoy más que nunca sabrá cumplir al pie de la letra su marcada misión. La Perla sabrá llenar su objeto primordial; y él debe ser el de propagar (...) la realización de todas aquellas instituciones que tiendan a nuestros engrandecimientos sociales. (...) Ella marchará por la vía del progreso marcando lentamente la obra de nuestra reorganización: que debe abrir paso a nuestro porvenir futuro". ${ }^{21}$

Por tanto, la inserción de la comunidad en la vía del progreso protagonizaba también los objetivos de La Perla, según lo que exponían sus redactores.

De este modo, los cuatro periódicos aquí reseñados, en diferentes años y momentos, tenían claro que la prensa era una herramienta de cambio social, de moralización y educación para una comunidad a la que decían representar pero a la que veían desunida, apática y alejada del "progreso", debido a supuestas viejas costumbres y malos hábitos. En este sentido, Stolcke $^{22}$ señala que una de las paradojas de la modernidad es la "culpabilización" de los menos "exitosos", casualmente en su mayoría personas racialmente diferenciadas gracias a categorías surgidas para ordenar la fuerza de trabajo en la economía-mundo capitalista. ${ }^{23}$ Una paradoja basada en la insistencia del liberalismo en la libertad e igualdad de oportunidades

19 Ibídem, "A la Juventud", 3 de mayo de 1878, cursivas en el original.

20 Ibídem, "Una palabra...", cursivas en el original.

21 La Perla, "Nuestro periódico", 8 de junio de 1879.

22 Stolcke, Verena: Racismo y sexualidad en la Cuba colonial, Alianza, Madrid, 1992.

23 Wallerstein, Immanuel: "El conflicto de clases en la economía-mundo capitalista", en Balibar, E., y Wallerstein, I. (coords.): Raza, Nación y Clase, IEPALA, Madrid, 1991, págs. 179-193. 
para todos dentro del ámbito de lo "civilizado". Así, quienes no logran el "éxito" socioeconómico son conminados a buscar en sí mismos las razones de su fracaso, ocultándose las relaciones de dominación existentes.

Completamente inmersos en esta línea de pensamiento que se imponía en un mundo encaminado con paso firme al capitalismo, quienes redactaban los periódicos deseaban o sentían tener la oportunidad de cambiar el presente y supuesto destino de su comunidad, ya que dirigirían instrumentos que podrían llevar al éxito o al fracaso del grupo. Básicamente, era a través de los editoriales donde se indicaban enfáticamente las ideas a ser inculcadas y los pasos que debían seguirse para alcanzar el deseado "progreso". Si bien no trabajaremos aquí estos editoriales, podemos decir que los ejes sobre los que insistían eran la fundación de asociaciones, la educación y confinamiento de la mujer al hogar, la motivación por el trabajo y el alejamiento del "vicio", el pulido de los modales y la mejora de la educación general, entre otros. ${ }^{24}$ Estos planteamientos eran acordes con los que se realizaban desde los grupos hegemónicos, que ponían en la "civilización" y el "progreso" los valores más preciados, desarrollando junto a ellos una serie de normativas acordes, de lo correcto y lo incorrecto. ${ }^{25}$

\section{Esferas públicas en diálogo pero en paralelo}

Si los afroporteños compartían con la sociedad en su conjunto la esperanza en el progreso social y confiaban en la prensa como motor de cambio, no se entendían menos importantes las reglas que debían utilizarse para poder discutir en la esfera pública. Sábato hablaba de una "liturgia lai$\mathrm{ca}{ }^{26}$ que precedía y abarcaba todos los actos públicos y movilizaciones, que también incluía las fórmulas que eran seguidas por los periódicos que formaban parte del entramado que permitía la construcción de la esfera pública burguesa.

En general, la emergencia o refundación de un nuevo periódico imponía a sus redactores un cordial saludo a la prensa que ya ocupaba espacio público, lo que era respondido por las publicaciones aludidas anunciando

24 Estos temas los desarrollamos en Geler, L.: ¿ «Otros» argentinos? Afrodescendientes porteños y la construcción de la nación argentina entre 1873 y 1882. Tesis de doctorado en Historia, Universitat de Barcelona.

25 Devoto, F., y Madero, M.: “Introducción”, en: Devoto, F., y Madero, M. (dirs.): Historia de la vida privada en la Argentina. La Argentina Plural: 1870-1930, tomo 2, Taurus, Buenos Aires, 2000. 26 Sábato: La política..., pág. 199. 
la salida del nuevo compañero. Siguiendo esta línea, los "saludos a la prensa" eran casi obligados y aparecían en los periódicos afroporteños cada vez que éstos se fundaban o reaparecían. También se hacían en retribución al saludo de un colega, lo que provocaba que a su vez se agradeciera, respondiendo a esos parabienes en el periódico en cuestión. Por ejemplo, si $\mathrm{La}$ Igualdad saludaba expresamente a los periódicos de su facción ("Tenemos el placer de retribuir a este distinguido colega y correligionario su cortés saludo a la prensa..."), ${ }^{27}$ La Juventud dedicaba su saludo a la prensa en general, una línea que seguirían todos los periódicos afroporteños que se conservan y que se declaraban independientes políticamente:

"Saludamos a toda la prensa en general, sin distinción de bandera ni color político, pidiendo tan sólo que traten con indulgencia a nuestros pobres escritos" ${ }^{28}$.

El saludo a la prensa no era un hecho a pasar por alto. En 1876, $L a$ Broma debía pedir disculpas por no haberlo incluido en su primer número, habiendo sido anunciada su aparición en otros periódicos:

\footnotetext{
"Desde las microscópicas columnas de nuestro semanario, nos hacemos el honor de saludar a los grandes atletas y pequeños periódicos de la prensa, especialmente a los que han tenido la fineza de anunciar nuestra aparición. Pedimos disculpas por no haber usado de esta debida cortesía en nuestro primer número, -involuntariamente, pues aunque tarde creemos ahora cumplir con un deber impuesto por las regla sociales. Salud!!". ${ }^{29}$
}

La Broma no volvería a olvidarse de la "debida cortesía". A partir de ese momento, cada una de sus reapariciones en la luz pública fue oportunamente acompañada del saludo de rigor y de los agradecimientos a los periódicos que dieran cuenta de ella. Pocas veces, sin embargo, podemos leer estos agradecimientos dedicados a los grandes periódicos, que parecían pasar por alto la fundación de las publicaciones afroporteñas. Existían, por supuesto, excepciones puntuales. La Nación anunciaba la reaparición de La Broma en diciembre de 1880, y en 1877 ya se había agradecido a $E l$ Porteño por dar el aviso respectivo..$^{30}$ De hecho, cada vez que surgía alguna referencia a las publicaciones afrodescendientes o a algún afrodescendiente en particular en los periódicos más importantes, como La Nación, La

27 La Igualdad, "El Autonomista", 3 de mayo de 1874.

28 La Juventud, "A la prensa", 1 de enero de 1876.

29 La Broma, "Salud!!", 11 de mayo de 1876.

30 Ibídem, "Noticias varias", 22 de noviembre de 1877, cursivas en el original. 
Tribuna, etc., se agradecía la deferencia, a veces incluso se reproducía el artículo, denotando tanto el escaso alcance que tenía la prensa afroporteña en un círculo más amplio, como también la importancia que se le otorgaba al hecho de ser nombrada en la esfera pública burguesa. Un ejemplo interesante de esto se dio en 1882, cuando se recogieron las rectificaciones realizadas por La Nación, La Tribuna Nacional y El Plata de una noticia en la que se acusaba a un grupo de afroporteños de participar en hechos delictivos, trascribiéndose la totalidad de los desmentidos, con sentimiento de gran alivio por parte de los periódicos por poder limpiar el nombre de los amigos en la esfera pública porteña en general y por supuesto en la afroporteña. ${ }^{31}$ Asimismo, en 1881, cuando en La Nación se anunció la fundación de una sociedad de socorros mutuos de la "clase de color", se reprodujo el artículo en su totalidad, agregando:

"Nosotros después de leer esta importante noticia, nos lanzamos a averiguar lo que hubiese de cierto al respecto, y hasta la fecha nada absolutamente hemos encontrado que nos de indicios favorables, por lo que creemos que el colega ha sido mal informado". 32

Evidentemente, la mención a la población afroporteña en los medios de comunicación más poderosos provocaba la reacción inmediata de los periodistas de la comunidad, ya fuera en la reproducción de las noticias, en los saludos o en salir a desmentir o verificar alguna noticia. No obstante, más allá de estos casos específicos o de los saludos de rigor que imponía la etiqueta periodística, la prensa afrodescendiente no solía aludir a los periódicos de fuera de su círculo. Si bien quedaba claro que los periódicos extra comunitarios eran leídos por los reporteros y directores de los afroporteños y que éstos estaban bien enterados de la cotidianeidad local, nacional e internacional, en general los periódicos afroporteños se volcaban casi exclusivamente en los acontecimientos que sucedían en la comunidad. ${ }^{33}$ Pero esto no quería decir que la prensa afroporteña no aspirara a formar parte de la esfera pública burguesa, tal como podemos apreciar en la ape-

31 Ibídem, "Solicitada", 12 de septiembre de 1882.

32 Ibídem, "Sueltitos", 27 de enero de 1881.

33 Una excepción a esto fueron los primeros números de La Juventud, en donde se publicaban noticias extraídas de otros periódicos con relatos de sucesos nacionales e internacionales, aunque esta iniciativa no durara más que algunos números. La Igualdad, por su parte, solía transcribir notas de otros periódicos, pero su carácter netamente político y proselitista la diferenciaba en esto del resto de las publicaciones. 
nada queja que reproducía La Broma y que dejaba constancia de la marginalidad de la esfera pública afroporteña:

“[a] nuestros poetas (...) nadie los conoce y se ignoran, por consiguiente, sus obras (...) ¿Quiénes, más que nosotros, leen (...) nuestros humildes periódicos, que jamás salen tampoco de nuestra fracción social?"”. ${ }^{4}$

La capacidad de circulación de los periódicos afroporteños estaba limitada a la propia comunidad, ante una sociedad que solía ignorar lo que sucedía en ella. Sin embargo, este frustrado deseo de ingresar en la esfera pública burguesa promocionaba que las estructuras de los periódicos comunitarios y extracomunitarios fueran bastante similares. Ambas, además de los saludos de rigor, incluían los editoriales, las noticias varias, las de última hora, las crónicas sociales (en los periódicos afroporteños todas estas secciones estaban siempre referidas a la comunidad) y los anuncios.

Así, aún dirigiéndose a un público reducido y siendo publicaciones en general marginadas del círculo de discusión más amplio, la prensa afroporteña seguía las formas "correctas" y establecidas de discusión en la esfera pública burguesa. Este cuidado formal posibilitaba que, llegado el caso, ambas esferas pudiesen coincidir e, inclusive, que si los periódicos de los grupos hegemónicos prestaban su apoyo, la esfera pública afroporteña pudiera llegar a mediar con el Estado y también mostrar un potencial poder contrahegemónico, como había sucedido con las protestas contra la discriminación de $1880 .{ }^{35}$ Simultáneamente, seguir las normas adecuadas permitía "educar" en los valores de la civilidad y participación ciudadana a la comunidad a la que estaban dirigidos.

Pero más allá de sus puntos en común, entre los periódicos se constatan continuas peleas y enfrentamientos que quedaban plasmados en grandes luchas editorialistas y en los desafíos y denuncias constantes que los periódicos se hacían entre sí.

\section{Periodistas, directores y redactores}

Tanto los directores como los redactores y colaboradores de los periódicos afroporteños mostraban actitudes personales muy beligerantes, tal original.

34 La Broma, "Cosas que nacen y mueren en el misterio", 30 de julio de 1881, cursivas en el 35 Geler: "La sociedad..."; Chamosa: Asociaciones africanas... 
vez debidas al compromiso que asumían de llevar a su comunidad a la senda del "progreso". Aunque en general lo hacían de forma anónima, ${ }^{36}$ desde sus publicaciones defendían las propuestas que ellos mismos emitían con ahínco, por lo que se les solía acusar de utilizar a esos periódicos como elementos personalistas, instrumentos para ganar espacio público e influencia en las decisiones que hacían a la comunidad.

En esta línea, Casildo G. Thompson, uno de los personajes con mayor prestigio y visibilidad dentro de la comunidad afroporteña, escribía en una carta dirigida al director de La Perla:

"La misión del periodista no se ha comprendido entre nosotros o ha sido adulterada cuando no radicalmente trocada. La misión del periodista ha sido corrompida por la podredumbre de las personalidades, desprestigiada por la ausencia de la ilustración y, en la mayor parte de las veces anulada por la usurpación ridícula que han hecho de ella hombres que no tienen ni tuvieron jamás la más simple noción de los deberes que impone, puesto que la prensa es la tribuna privilegiada desde donde se emiten las más serias y trascendentales ideas y no el circo en que los polichinelas excitan la hilaridad popular". ${ }^{37}$

Las ideas vertidas por Thompson nos recuerdan a la "misión apostólica del periodista" de la que hablara Halperín Donghi ${ }^{38}$, aceptadas y retomadas por los periodistas afroporteños, al igual que la importancia de la prensa.

Con una marcada autocrítica, La Broma se hacía eco de estas ideas que circulaban por la comunidad en un editorial publicado con motivo del anuncio de la reaparición de La Perla y de El Aspirante, a quienes quería aleccionar con su ejemplo sobre cómo hacer buen periodismo:

"Provocados algunas veces con injusticia e impropiedad no hemos podido resistir a la violencia del ataque (...) Pero bien lo comprendemos, esa no es la misión del periodista, la prensa nunca debe servir de arma para ensañarse en una personalidad ni levantar la propia. Los intereses comunes no se pueden olvidar ni un solo instante y a ellos debe ser nuestra contracción, porque ellos reclaman el deber de nuestra lealtad". ${ }^{39}$

36 Aunque podemos identificar a la mayor parte de los dueños y directores de los periódicos, casi todas las noticias se publicaban de forma anónima.

37 La Perla, "Esto es digno de imitarse", 6 de octubre de 1878.

38 Halperín Donghi, T.: José Hernández y sus mundos, Sudamericana, Buenos Aires, 1985, pág. 161 .

39 La Broma, "Notas editoriales", 13 de enero de 1882. 
De este modo, si el periodismo se pretendía como un apostolado para servir a la comunidad, el reverso de este ideal era que los periódicos se utilizaban como herramientas de discusión y defensa de ideas personales, provocando debates y luchas permanentes. Y si bien existían momentos de acercamiento, las peleas entre ellos siempre reaparecían. De hecho, buena parte de los relatos de sucesos locales consistían en criticar a los otros periódicos o en anunciar sin falta las desapariciones o los retrasos en la aparición o distribución de alguno de ellos, sobre todo si se trataba de rivales. También se informaba si se producían renuncias o cambios en sus redacciones, o cualquier hecho que se considerara relevante, muchas veces con sorna o complicidad, demostrando que el periódico que seguía en circulación era mejor y contaba con mayor número de suscriptores que sus competidores.

En varias ocasiones a lo largo de los diez años de prensa afroporteña que estudiamos surgieron propuestas de unir en uno solo a todos los periódicos de la comunidad. Esa concentración era el principal argumento que se esgrimía para pedirlo, en contra de la utilización personalista de las publicaciones que "dividía" a la comunidad y la enfrentaba.

La Juventud había instado a esa unificación en 1878, entendiendo que en la multiplicidad de periódicos se encontraba la causa de los males que sufría la sociedad, ya que forzaba la desunión y el "verdadero atraso moral":

“... nosotros pensamos que esos elementos dispersos, fraccionados, que nada dicen y a nada responden, son precisamente un inconveniente para nuestro futuro progreso (...). Un periódico serio, de responsabilidad, que debidamente nos represente ante la opinión sensata del país, es lo que necesitamos. Es necesario pues, trabajar para reunir en un solo punto y bajo una sola aspiración, esos elementos dispersos y fraccionados, y entonces, recién entonces, tendremos el derecho de darle al cuerpo reposo y al corazón descanso". ${ }^{40}$

Si por un lado el artículo hacía hincapié en que la prensa representaba a la comunidad ante la opinión pública, una posibilidad de ingreso en la esfera pública burguesa o por lo menos el único medio de visualizarse en ella, por el otro criticaba la diversidad de medios existentes — que es lo que caracterizaría en general al juego de la opinión pública - y llamaba a la unión comunitaria, una de las banderas más importantes que los periódicos afroporteños no se cansaban de agitar, aún en los momentos más álgidos de

40 La Juventud, "La hora del trabajo", 10 de febrero de 1878. 
peleas. No se hizo nada desde La Juventud por lograr esta unión, sino todo lo contrario, y los periódicos siguieron sus caminos rivales.

Casi un año más tarde, volvía a salir a la luz pública la petición de que hubiera sólo un periódico en beneficio de la unión de la comunidad afroporteña. Lo hacía el articulista cuyo seudónimo era "Genaro" para $\mathrm{La}$ Broma, donde insistía en el problema del personalismo:

"Si se trata de un periódico sucede lo mismo. «Pedro» no quiere escribir en el semanario que dirige «Juan» por no ocupar un puesto secundario, y como cada uno quiere ser redactor en jefe, es necesario den a luz varias publicaciones, a fin de satisfacer la vanidad de cada aficionado (...) Empecemos por ejemplo, por reducir a una sola las explotaciones semanales que ven la luz entre nosotros. Hagamos un esfuerzo en este sentido; olvidemos nuestras rencillas y llamemos al trabajo a todos los jóvenes inteligentes de nuestra sociedad, de entre ellos nombremos el más capaz para que dirija en jefe esta publicación, en que colaboremos todos". ${ }^{41}$

El deseo de Genaro despertó la respuesta enérgica de La Broma y también de La Perla. Si el primero comenzaba aceptando que tener una sola publicación sería más sencillo, puesto que los periódicos afroporteños debían afrontar serias dificultades económicas para continuar apareciendo, después, sin embargo, insistía en que eso sería "imposible" y "ridículo". Las razones que esgrimía era que deberían hacer un periódico más grande y con mayor frecuencia de aparición, y por lo tanto más caro, lo que perjudicaría a los bolsillos de las familias afroporteñas. Así, calculaban:

"Le garantimos a Genaro (...) que es más adecuado que pague quien pueda veintiséis pesos mensuales y tenga tres publicaciones diferentes, y no que paguen quince o veinte por un periódico que lo repetimos: sería ridículo porque las diferentes manifestaciones de la juventud que dedica a hacer algunos ensayos, tendrían que estar sujetas al juicio del director o redactor en jefe". ${ }^{42}$

Si bien La Broma intentaba dar una explicación económica a su negativa a la existencia de un único periódico afroporteño, terminaba admitiendo que el problema era la dirección de él, tal como había expuesto Genaro en su artículo. La respuesta de La Perla fue más enérgica:

“...supongamos que existiesen ahora dos o tres periódicos, o cinco, todos estos no podrían manifestar más que una sola idea, y con ese motivo la suya misma que la viniera a exponer por medio de la prensa, no tendría aceptación por parte del redac-

41 La Broma, "Colaboración", s/f de diciembre de 1878.

42 Ibídem, "Oiga Genaro", 11 de enero de 1879. 
tor; nombrar un redactor en jefe, según Vd. propone y cada uno de los demás fuese fulano, zutano o mengano, tendría que someter su idea y voluntad a la del redactor en jefe (según el articulista Genaro) único modo de poder darle una marcha regularizadora a nuestra prensa periodística (...). [E]l señor yenaro no sólo nos da un consejo absurdo, sino que se desmanda groseramente (...), porque sólo una cabeza hueca puede verter de su mente una tan mal inspirada creencia". ${ }^{43}$

Nuevamente el tema del único redactor en jefe se mostraba como el obstáculo principal a la propuesta.

Así, aunque el personalismo era criticado, no se entendían a los periódicos sin ese elemento, lo que contribuía a erigir a sus directores o redactores en personajes de importancia, que a su vez luchaban por captar la mayor cantidad posible de público lector que sostuviera económicamente a las publicaciones. De hecho, la forma tan contundente en que La Perla contestaba al articulista -incluso acentuando la pronunciación italiana ("yenaro") $)^{44}$ del seudónimo que éste había elegido para escribir, extranjerizándolo- llama la atención. Curiosamente, La Perla y La Broma unieron sus redacciones en el año 1879 durante un tiempo, pasando Dionisio García (director de La Broma) a la redacción de La Perla. Este experimento duró sólo unos meses (de marzo a junio), y no tenemos constancia de que sucediera en alguna otra ocasión y con algún otro periódico.

Otra de las denuncias que se solían hacer los periódicos entre sí era la de querer obtener beneficios materiales con las "empresas periodísticas". Si bien esta denuncia parece irrisoria debido a las constantes quiebras y cierres de los periódicos por falta de dinero, debemos examinarla con atención.

En líneas generales, Quesada ${ }^{45}$ indicaba que la redacción, la dirección y la administración de los periódicos solían ser gratuitas, ya que las empresas aspiraban a que la suscripción alcanzara simplemente para cubrir los gastos materiales. Los anuncios eran, según Quesada, el quid del mantenimiento de los periódicos, a todas luces una empresa que no rendía frutos económicos ya que, tal como sucedía con las publicaciones afroporteñas, debían superar la falta de pago de las suscripciones.

En nuestro caso, además de cobrar por la publicación de los artículos enviados por los lectores y de los anuncios que solían aparecer con bastantes altibajos, existían diversas maneras de ingresar o de ahorrar dinero a las

43 La Perla, "Don Genaro", 15 de febrero de 1879, cursivas en el original.

44 Recordemos que en Buenos Aires las letras "ye" tienen la misma pronunciación que las letras "ge" en italiano.

45 Quesada, Ernesto: "El periodismo argentino (1877-1883)", en: Nueva Revista de Buenos Aires, año 3, tomo 9, Buenos Aires, 1883, págs. 72-101. 
empresas. Una de ellas era que, en muchos casos, la impresión y/o distribución de los periódicos eran realizadas directamente por los redactores, con el ahorro consiguiente de dinero de sueldos en ese rubro. En La Broma se aludía comúnmente a que la distribución era realizada por el mismo director o por sus colaboradores, que cobraban personalmente las suscripciones atrasadas. Por ejemplo, en una noticia muy interesante por la comparación que establecía y porque dejaba claro el alto grado de compromiso que tenían los redactores con su periódico, se relataba que el New York Herald había comenzado siendo repartido por su redactor, quien además lo imprimía, para agregar:

"Hoy como todo el mundo sabe, el New York Herald es el diario más popular del Universo y su redactor goza de una gran renta diaria (...) [P]or cierto que nosotros no llegaremos a esa altura, pero se nos ocurrió hacer esta especie de cuento porque alguien critica nuestro proceder cuando nos ve con el hermoso paquete de Bromas debajo del brazo, repartiéndolas a nuestros favorecedores. Hemos dicho y repetiremos, siempre que se nos dispense la protección que actualmente se nos presta, no tendremos inconveniente en hacer todo lo que esté a nuestro alcance con tal de que nuestra comunidad tenga un periódico como sus exigencias lo reclaman. Tableau!". ${ }^{46}$

Entre las distintas estrategias para ingresar dinero con el objetivo de mantener en circulación las publicaciones se cuentan la utilización de los periódicos para promocionar los propios negocios paralelos de los periodistas o la impresión de los ejemplares en los lugares de trabajo. Si Juan Finghlay - director de $L a L u z$ - era él mismo tipógrafo y trabajaba en una imprenta, los directores de La Perla - Camilo Olivera y los hermanos Luis y Guillermo Ramírez- se anunciaban en su periódico ofreciéndose para la realización de trabajos de impresión. Asimismo, se publicitaban cigarrerías (como la de Juan Pablo Balparda, redactor de La Juventud), pomos para el carnaval (negocio de Dionisio García, director de La Broma), etc. Del mismo modo, los periódicos realizaban frecuentes intercambios, como lo muestran las repetidas publicidades de las distintas imprentas donde se iban confeccionando.

Pero creemos que no debemos subestimar el móvil económico a la hora de tratar de entender las peleas entre los periódicos afroporteños. Si hacemos cuentas rápidamente con los datos que tenemos, es posible que los directores y redactores de periódicos sí estuvieran interesados en la publicación de éstos como medio de vida. Según el cálculo hecho por un redac-

46 La Broma, "Noticias varias", 3 de agosto de 1879, cursivas y francés en el original. 
tor de La Broma en 1878, con 400 pesos había suficiente dinero para hacer dos tiradas del periódico. ${ }^{47} \mathrm{Si}$ aceptamos las cifras de suscriptores que ellos mismos daban (lo veremos específicamente en próximos apartados) y suponemos que cada impresión se hacía por 300 ejemplares, entonces la impresión de cada periódico rondaría los 0,66 pesos. Hipotetizando una suscripción media - a la baja - al periódico de 200 personas, y con una suscripción mensual de 10 pesos (lo que costaba en 1879) y cuatro periódicos por mes, imprimiendo 300 ejemplares el gasto de producción sería de 792 pesos, mientras que el ingreso total sería de 2.000. Si bien es obvio que los periódicos no eran una empresa continuadamente rentable $-\mathrm{y}$ esto se ve claramente en los cierres e interrupciones constantes de los mismostambién es cierto que podían llegar a serlo. La diferencia entre el costo y la entrada de dinero en el cálculo anterior alcanzaría para que algunos de los redactores hicieran si no un sueldo completo, por lo menos una ayuda complementaria en sus ingresos mensuales. La referencia la tomamos aquí del presupuesto elaborado por la Legislatura de la Ciudad de Buenos Aires para el año 1879, que fijaba el sueldo de un ordenanza en 750 pesos..$^{48}$

Pensamos que el interés y la lucha que entablaban los distintos directorios de los periódicos entre sí, además de enfrentar a hombres con posiciones políticas fuertes, con ideas muy personales sobre su comunidad y con cierto ansia de prestigio, bien podía deberse también a que el periodismo se considerara una empresa rentable — tal vez como el New York Herald - , por lo menos durante algún tiempo, algo que se contradice con las denuncias que se hacían entre sí. Para los periodistas afroporteños la prensa era tanto una posibilidad de conseguir el éxito personal - económico y simbólico - como un camino de progreso y civilización para la comunidad a la que querían conducir, lo que multiplicaba el número de publicaciones y aumentaba las peleas entre ellas.

Así, aún invistiéndose del apostolado periodístico y trabajando por el cambio y "regeneración" de los afroporteños, los directores y redactores de los periódicos no cedían espacio en su lucha por la representación de la comunidad en la contra esfera pública subalterna y, en última instancia, en la esfera pública burguesa. En una sociedad que tejía sus redes según la lógica de la discusión en la esfera pública, quien poseyera la posibilidad de acceso a ella detentaría una gran cuota de poder, especialmente si nos cen-

47 Ibídem, “¿Por qué se llama La Broma? IV”, 15 de noviembre de 1878.

48 Actas de las Sesiones de la Municipalidad de la Ciudad de Buenos Aires en 1878, Imprenta de "El Nacional”, Buenos Aires, sesión del 10 de octubre de 1878, página 349. 
tramos en una comunidad marginada social y económicamente. El nivel de prestigio que otorgaba dirigir un periódico ubicaba a sus directores, fundadores y colaboradores en un lugar privilegiado en la sociedad afroporteña y posicionaba a sus redactores en la situación de ejercer de "intelectuales subalternos", ${ }^{49}$ sujetos capaces de coordinar acciones colectivas y con capacidad de negociación con los otros grupos, incluidos los hegemónicos. De este modo, los intelectuales subalternos pugnaban por hacer oír sus opiniones - y por vender más periódicos- y cada cual desde su lugar exhortaba, generaba o proponía cambios desde sus páginas (fundación de asociaciones, de colegios, participación en distintos eventos, difusión de obras literarias, etc.) de acuerdo con la idea de que los periódicos eran instrumentos potenciadores del cambio social, lo que erigía y visibilizaba a ciertos personajes relacionados con el mundo periodístico que comenzaban - de esta manera- a detentar poder sobre su comunidad.

\section{Los periódicos y sus lectores}

Como parte de su tarea educadora y civilizadora, los periódicos afroporteños ofrecían sus columnas a la participación de los lectores - hombres y mujeres - para que enviaran artículos que tuvieran que ver con el "bien común", pero también sus producciones artísticas (poemas, versos, cuentos), opiniones y cartas personales. Igualmente, se brindaban para que las asociaciones - que asimismo eran consideradas una forma de socialización ligada al progreso y a la civilización $-{ }^{50}$ pudieran tener un espacio para convocar a sus socios o aspirantes a las reuniones, asambleas, votaciones, manifestaciones, etc. Sin embargo, los periódicos establecían una diferencia tajante entre las aportaciones que tuvieran que ver con el "bien común" y las que fueran de carácter personal: los artículos que hicieran un servicio a la comunidad se publicarían gratis, el resto no. Esto sucedía y era aclarado en todos los periódicos. Incluso La Broma advertía directamente de que retendría originales hasta que se pagara por la publicación de los mismos:

49 Feierman, Steven: Peasant Intellectuals. Anthropology and History in Tanzania, The University of Wisconsin Press, Madison, 1990.

50 Sábato, Hilda: "El fervor asociativo", en: Di Stefano, Roberto; Sábato, Hilda; Romero, Luis Alberto, y Moreno, José Luis: De las cofradías a las organizaciones de la sociedad civil. Historia de la iniciativa asociativa en Argentina 1776-1990, Gadis, Buenos Aires, 2002, págs. 104-131. 
"Les hemos observado mil veces! A los que piden la publicación de solicitadas, que si estas no vienen en forma, es decir, con sus correspondientes Gastelumendis, no les daremos publicidad". ${ }^{51}$

Encontramos aquí una primera dificultad para esta "igualdad" de acceso al espacio de participación —a la esfera pública subalterna— que se proponía desde las páginas de las diferentes publicaciones, tanto como sucedía con el acceso a la esfera pública burguesa. Una segunda dificultad, muy relacionada con la primera, era la posibilidad de suscripción a los periódicos para una comunidad que, en líneas generales, contaba con muy poco poder adquisitivo. Las constantes quejas que se pueden leer durante los diez años de publicaciones afroporteñas acerca de la falta de pago de muchos de los suscriptores dan ejemplo de ello. Por ejemplo, en $\mathrm{La}$ Juventud se increpaba a los morosos:

"A los suscritores morosos- Les ponemos en conocimiento que la empresa de este semanario ha dispuesto que todo suscriptor que no abone hasta los dos meses vencidos, se suspenderá inmediatamente la remisión del periódico". ${ }^{52}$

O en La Broma, que exponía claramente las consecuencias de los impagos:

"Hoy cumple seis meses nuestro periódico, durante su existencia han fallecido otros. Al hacer esto presente se nos ocurre recomendarle a los suscriptores morosos más exactitud en el pago". ${ }^{53}$

Estos impagos provocaban, como se puede leer en la cita anterior, el cierre abrupto de las publicaciones, que lograban reaparecer mediante nuevas suscripciones o gracias a la organización de bailes a beneficio, de los que también hay ejemplos para todos los periódicos y para todos los años. La Broma hacía su beneficio anual que daba aparentemente buenos resultados. Lo mismo hacían La Juventud, El Aspirante y La Perla y las descripciones de los preparativos y de los bailes ocupaban varias páginas de las crónicas sociales cuando se producían.

Si nos preguntamos cuántos suscriptores tenían los periódicos, existen pocas cifras. La que más hablaba de esto era La Broma, que nos ofrece varios datos que hay que considerar casi sin dudarlo "inflados", ya que eran

51 La Broma, "Sueltitos de costumbre", 25 de noviembre de 1881, cursivas en el original.

52 La Juventud, "Sección noticiosa", 5 de marzo de 1876.

53 La Broma, "Varillazos", 11 de marzo de 1878. 
un modo de hacer propaganda frente a los periódicos rivales. Así, el 8 de noviembre de 1877 La Broma anunciaba que tenía 486 suscriptores, supuestamente el mayor número en toda la historia de la comunidad. A comienzos de 1878, exponía que "los quinientos abonados que religiosamente la sostienen, están poseídos y poseídos están de que esta publicación es necesaria" ${ }^{54} \mathrm{El} 25$ de julio de 1878 decía contar con más de 200 suscriptores y ese mismo año, publicaba el 10 de octubre un suelto en el que se hacía alusión a los 500 ejemplares que se editaban del periódico. Para el 6 de marzo de 1881, La Broma decía tener suscritas a más de 300 personas.

Tenemos datos también de La Perla, que el 8 de mayo de 1879 (en circunstancias en que La Broma y La Perla se habían unido en una sola publicación) anunciaba 329 suscriptores, hecho que animaba a los directores a intentar editar el periódico semanalmente.

Estos números, aún tomándolos a la baja, nos están hablando de un gran interés en la comunidad por acceder a la información y a las discusiones que se veían reflejadas en los periódicos, por participar, en definitiva, de la imaginación comunitaria que permitían crear. Además, la pobreza de los lectores era paliada en parte con estrategias que - aunque condenadas desde los periódicos - permitían a una buena parte de la comunidad acceder a este medio de comunicación, generando a su vez más vínculos solidarios y nuevas prácticas de sociabilidad grupal. Estamos hablando del "leer de ojito", es decir, leer el periódico de prestado, o en grupo, o por encima del hombro ajeno. Este "problema" se solía exponer con bastante ironía. Por ejemplo, en la cita que sigue se lo comparaba con fumar "de prestado", según una discusión ocurrida en el club social al que pertenecían los redactores de La Broma, el Club Retirada:

“... en la última asamblea del mencionado Club, tratándose de los lectores de ojito, se acordó también en las precauciones generales, observar por regla de conducta no invitar a nadie con fumantes ¡ a nadie! Es un golpe mortal para los fumadores de ojito. Oh!!! Si pudiéramos hacer lo mismo con los lectores". 55

Para el caso de las lectoras femeninas, también se había detectado este comportamiento en la lectura de La Broma, al que se solía llamar "el chiche" de la comunidad:

54 Ibídem, "Un paréntesis", 3 de enero de 1878.

55 Ibídem, "Varillazos", 10 de octubre de 1878, cursivas en el original. 
“... estoy seguro que si todas las señoritas no son suscriptoras del Chiche, por lo menos lo leen todas, tu sabes, de que en una casa que hay dos o más personas es imposible, que todos lo tomen, pero que lo lean es indispensable". ${ }^{56}$

La lectura de "ojito" siguió molestando al periódico en los años sucesivos, como vemos en este suelto de La Broma de 1881:

"Hacemos presente a los suscriptores que nos adeudan más de dos meses, que aunque con sentimiento nos vamos a ver en la necesidad imperiosa de pasarles una... rayita, pues no es propio que haya suscriptor que se esmere de todos modos para sostener este papelito, como cariñosamente le llaman nuestros amigos, mientras otros siguen apareciendo suscriptores y leyéndolo de $o j o " .{ }^{57}$

Pero no eran solamente los periódicos los que condenaban esta práctica, sino que los propios lectores interesados en el sostenimiento de las publicaciones comunitarias se organizaban y llevaban adelante iniciativas para romper con ella. Sucedió con un grupo de lectoras de La Juventud en 1878. Estas mujeres convinieron:

“...con el mayor número posible que sea de personas, para no dar PRESTADO, NI POR EL MOMENTO, al periódico «La Juventud», obligando de cuyo modo a los que se interesan en leerlo, se suscriban a él, o bien compren el número suelto, (...) no permitiendo desde ya, que ninguna persona lea el periódico de ojito. Igualmente se previene que esta prohibición la pueden hacer los caballeros buenos amigos, que han compartido los trabajos con los miembros de la Comisión Directiva. Confiamos en el éxito". ${ }^{58}$

La Juventud acababa de volver a la arena periodística después de un 1877 casi sin publicar, y obtenía por medio de la suscripción popular los medios para su reimpresión. Seguramente ésta era la razón por la que sus suscriptoras velaban con tanto celo su continuidad y deja ver además un alto grado de "fidelidad" entre suscriptores.

Así, si consideramos que la lectura de "ojito" era un hecho, se puede multiplicar la cifra de lectores de los periódicos, conformando un número muy amplio de personas integradas "imaginariamente" en la comunidad. Esto también lo sabía La Broma, cuando calculaba irónicamente:

56 Ibídem, "Varillazos", 24 de octubre de 1878, cursivas en el original.

57 Ibídem, "Sueltitos de costumbre", 28 de mayo de 1881, cursivas en el original.

58 La Juventud, "Hechos locales", 31 de enero de 1878, mayúsculas en el original. 
“... la suscripción aumenta notablemente, pues si antes lo leían mil quinientas o dos mil personas, hoy garantimos que cuenta con doble cantidad de lectores, por cierto, un ocho por ciento de ojito"..$^{9}$

Esta gran masa lectora de los periódicos afroporteños se veía identificada de algún modo u otro por estas publicaciones, las cuales lograban que sus suscriptores los apoyaran. Más allá del evidente interés que podía generar el intercambio de información sobre la propia comunidad, creemos que un interesante modo de acercamiento de los periódicos a sus lectores era el lenguaje que se utilizaba en sus columnas. Si bien en las editoriales el tono era en general severo y rígido, había pocos errores gramaticales y estaba más cuidada la elección del vocabulario que se utilizaba - que además tenía un tono plenamente educativo y disciplinador (en consonancia con los objetivos que se fijaban los periódicos en sus manifiestos fundacionales) - , el resto se escribía en un lenguaje muy coloquial e irónico que incluía el voceo (hablar de "vos"), y muchas expresiones del habla cotidiana, constituyéndose en un reservorio vastísimo del habla popular de la Buenos Aires que recibía a miles de inmigrantes y cambiaba por minutos. Venimos leyendo muchas de estas maneras "de hablar" que quedaban plasmadas en sus hojas pero queremos, sin embargo, hacer notar que este lenguaje no se deslizaba al azar en las publicaciones. Por el contrario, los redactores de los periódicos verificaban cada una de las cosas que se publicaban y corregían, de ser necesario, los originales que llegaban de los lectores. Justamente, nos enteramos de esta situación porque La Broma accedió repetidas veces al pedido de publicar "tal cual" unos poemas de Tomás Rivero, al que llamaban sarcásticamente "el vate":

"Leed, mis bellas, leed: -que Rivero me encarga que tenga mucho cuidado con el cajista, que se le publiquen sus versos, tal cual el original, sin errores, como están, para que según él puedan leerse"

Estos versos solían estar escritos con muchas faltas de ortografía y sin seguir regla gramatical alguna. Un ejemplo de los de Tomás Rivero se puede ver en la siguiente estrofa de uno de sus poemas:

59 La Broma, "Varillazos", 15 de abril de 1880

60 Ibídem, "Varillazos", 20 de marzo de 1881. 
"yo asisti adicho vaile/ que me en vitaron ami/ y era triste que un desaire/ tuve pronto que sufril// mi amor no me sujecta/la pacion de un mosó honrrado/el continuo la flor de un poeta/ sera, amante triste y desairado (sic)". ${ }^{61}$

Durante todos los años de publicación de La Broma, los versos de Rivero fueron objeto de risas y burlas. No solamente las faltas de ortografía y gramática se hacían graciosos — aún para la época-, sino los contenidos de sus poemas aparecían como hilarantes:

"Conduélete de mí, ¡caro Rivero! Que te vea yo parar las orejas y abrir... la boca, para lanzar tu canto sonoro y vibrante como el rebuzno, cadencioso como el rugido del tigre, rumoroso, como el gruñido del chancho, armonioso, como el balido de un toro (sin alusión)". ${ }^{62}$

Que los poemas de Rivero siguieran publicándose a petición y forma del autor era porque éste pagaba sin falta al periódico, según los propios dichos de La Broma. Suponemos que no escribía de este modo a propósito - como un divertimento - ya que a menudo se publicaban versos "en pardo"63 pero con una clara intención jocosa y para los que no se indicaba que no habían sido corregidos o que habían sido publicados textualmente por petición del autor.

El cuidado que se ponía en la edición de los periódicos se retrataba también en las disculpas que se solían pedir cuando había errores de imprenta, como sucedía en 1878:

"A nuestros lectores- Motivos ajenos a mi voluntad me impiden que aparezca este semanario con las correcciones debidas; por tanto pido a los lectores de La Broma tengan a bien salvar la multitud de errores de que plagado va este número, prometiéndoles que en adelante pondrá todos los medios a su alcance la redacción de que formo parte". ${ }^{64}$

La corrección de errores tipográficos, ortográficos y gramaticales muestra que las ediciones eran pensadas, diseñadas y revisadas esmerada-

61 Ibídem, "Varillazos", 22 de noviembre de 1877.

62 Ibídem, "Varillazos", 16 de junio de 1882.

63 Suplantar la "r" final de las palabras por la "l", como en "sufril", era una de las características del "habla parda", una forma de hablar que caracterizaba a la población más humilde entre los afroporteños; "una media lengua", según la describe Rodríguez Molas, que era exaltada en los años de gobierno de Rosas. Rodríguez Molas, Ricardo: "Condición social de los últimos descendientes de esclavos rioplatenses (1852-1900)”, Cuadernos Americanos, vol. CXXII, México, 1962, págs. 133-171.

64 La Broma, "Noticias varias", 6 de diciembre de 1878. 
mente. Pero el caso de los chistes que se gastaban a Rivero nos retrotrae también al tema del poder que ejercían los periódicos desde sus columnas, de exponer en la esfera pública, de denunciar, vapulear, criticar, engrandecer o ensombrecer tanto a personas como a hechos. Sus denuncias tenían consecuencias, y esto les permitía ejercer un gran control social.

\section{El "panóptico" de la regeneración}

El extraordinario poder que, creemos, acumulaban estos periódicos como propulsores de cambio los llevaba asimismo a erigirse en "guardianes" de las conductas apropiadas para efectuarlo.

Al pensar en el dispositivo panóptico detallado por Foucault ${ }^{65}$ nos imaginamos un centro de vigilancia omnipresente, que todo lo ve pero cuya función de vigilancia comienza a hacerse invisible por el grado de generalización y de introyección que su uso provoca. Y no encontramos esto tan diferente a lo que sucedía con los periódicos afroporteños. De hecho, cuando el autor describía el sistema de vigilancia y control del panóptico enfatizaba cuán amplificado y difundido en el cuerpo social se encontraba ya desde el siglo XVII, acentuando su función generalizada y de soporte para la consolidación de la sociedad disciplinaria, en la que el Estado actuaba con un poder invisible y diseminado. Para los lectores de los periódicos afroporteños era importante aparecer mencionados en los relatos de los bailes y tertulias, por ejemplo, y no lo era menos el hecho de aparecer evaluados de forma positiva - o por lo menos sin comentarios alusivos-, ya que los periódicos se dedicaban número tras número a amonestar a quienes consideraran que se habían comportado incorrectamente, o por fuera de las normas. La idea de que se tenía "derecho" a denunciar, y de que ese derecho se utilizaba en beneficio de la comunidad, quedaba retratada en las siguientes frases:

"[L]os asuntos sociales que tocamos es porque los conocemos, las cuestiones que en la sección correspondiente se ventilan y que no dejan de tener su interés común con nuestras necesidades, son perfectamente garantidas y pertenecen a apersonas idóneas que saben donde les aprieta el zapato, como vulgarmente se dice, con que así creemos que nuestro servicio satisfará a nuestros favorecedores". ${ }^{66}$

65 Foucault, Michel: Vigilar y castigar. Nacimiento de la prisión, Siglo XXI, Madrid, 2005.

66 La Broma, “Por qué se llama La Broma?”, 24 de agosto de 1879, cursivas en el original. 
"Ventilar" las cuestiones sociales era algo que los periódicos afroporteños hacían cada vez que se publicaban, a través de las distintas secciones de noticias sociales. Asimismo, los que informaban y los denunciados sabían donde les "apretaba el zapato". Ambas expresiones son muy elocuentes y muestran que la denuncia pública estaba dentro de las actividades que las publicaciones se proponían llevar adelante sin ningún tipo de autolimitación, como parte incluso de la misión periodística para guiar el cambio social.

En general, los señalamientos públicos se hacían tanto directamente como de forma solapada, comúnmente en tonos irónicos y en composiciones burlescas que mencionaban nombres con iniciales o seudónimos. Algunos ejemplos son los "sueños" que aparecían en La Broma:

"Soñé de que Pancho López/con su reverenda calva,/hablaba a cierta chiquilla/de corazón y de alma.// Y que el tal chico quería/comer una cierta fruta/que aunque le está prohibido/comerla, siempre le gusta (...)// Soñé que el chinito Carlos/que se apellida Delzar/ocurrió a hacerse inscribir/con un cierto juez de paz. // Mas viéndolo tan bonito/el señor juez se negó/a inscribirlo, y el chinito/tomó la puerta y volooó!”. ${ }^{67}$

O las "bromas de La Broma":

"Pobre J. Fhinglay si se casará, en el presente año o en Carnaval. Esto por "La Broma" pronto se sabrá (...). // Pobre F. P. Bello, como sentirá de que ño D. Malo le privó el cenar. Ah! -esto por «La Broma» se ha de averiguar". ${ }^{68}$

Sin embargo, en ambos casos los nombres se adivinaban fácilmente: Francisco López, Juan Finghlay, Carlos del Sar, Froilán P. Bello y Dionisio Malo. Esto, evidentemente, reforzaba la sensación de peligro de los lectores de cara a la posible denuncia pública. Debemos destacar, además, que se entrevé en el primer ejemplo la discriminación del juez de paz al "bonito" Carlos del Sar, algo que La Broma no parecía rechazar de plano, inculcando implícitamente formas de "presentarse" acordes con las ideas de progreso y civilización promovidas desde los grupos hegemónicos.

Pero no siempre era el tono jocoso lo que predominaba en las denuncias. En El Unionista se hacía la siguiente advertencia a una "matrona" de la comunidad:

67 Ibídem, "Varillazos", 2 de diciembre de 1881, cursivas en el original.

68 Ibídem, "Sueltitos de costumbre", 25 de agosto de 1882, cursivas en el original. 
"Advertencia -A quien corresponda. Se asegura (...) que una señora encargada de (...) ciertos objetos destinados a un fin humanitario, reúne personas (...) para censurar mordazmente la mayor parte de las obras [donadas] (...). Con más datos volveremos sobre el asunto, si fuese necesario, para extirpar estos abusos indignos". ${ }^{69}$

La amenaza de El Unionista mostraba el poder que se sabía detentaban los periódicos. Dar a la publicidad un caso o una situación, exponer en la contra esfera pública era un poder del que se hacía gala y que se utilizaba abiertamente. No publicar nombres en principio parecía ser la primera advertencia dada a los que no cumplían con las reglas de conducta adecuadas. Y esta coacción indudablemente era sentida por los implicados. En $\mathrm{La}$ Juventud, después de una denuncia expresa que el periódico había publicado contra alguien que "difamaba" a uno de sus colaboradores, se divulgaba una carta aclaratoria firmada por el acusado:

"Un arrepentido -Nuestros lectores han de recordar del hecho local que dimos cuenta en esta misma sección. Pues a efecto de lo mismo hemos recibido (...) una carta del caballero ese, que con tanta valentía insultaba (...). En ella manifiesta que él jamás una cosa tal cometió, agregando (...) estas palabras que las hemos trascripto (...):-«Yo caballero soy víctima de una infame calumnia; (...) [no soy] denigrador de un joven que la posteridad lo ha de respetar» (...) Si ahora no lanzamos a la picota el nombre de la persona; es por respeto a sus nobles sentimientos". ${ }^{70}$

Evidentemente, una pelea con el redactor de un periódico podía ser muy perjudicial y llevaba a los acusados a realizar arrepentimientos públicos para lavar su nombre.

Como vemos, "lanzar a la picota", "extirpar abusos", etc., eran las imágenes que ilustraban el gran poder desarrollado por estos periódicos y sus redactores, amenazando con exponer a la publicidad ciertos hechos o personas. Una sociedad del control cuyo dispositivo para "mirar" eran los periódicos. La conciencia de esa fuerza quedaba clara también en noticias que nada denunciaban, escritos jocosos que se publicaban como cuentos o como relatos, pero que podían incluir diálogos como el que sigue:

"Eduarda -Hay visitas Dorila?

Dorila -Sí, están los REPORTERS de "La Perla"

Ramonita $-i$ Vengo bien che Dorila?, ay que no me vayan a sacar en el...... que nada se les escapa. (...)

69 El Unionista, "Noticias varias", 9 de diciembre de 1877.

70 La Juventud, "Hechos locales", 20 de abril de 1878. 
Eduarda -Perfectamente, no me arrastra la cola, fijáte no sea que estos de....... tengan algo que criticarme" $"$.

Era una advertencia, en tono risueño, de la omnipresencia de los periódicos. El sistema de reporteros que todos decían tener, y que eran enviados a la mayor cantidad posible de tertulias y bailes que se realizaban en la comunidad, garantizaba que la información de todo lo que sucediera en ella llegara a ser relevada y evaluada por los redactores. Las listas de los asistentes a los bailes y los relatos pormenorizados de todo lo que allí sucedía no podían faltar en la prensa afroporteña. A veces, incluso, se publicaban relatos en los que se indicaba que los reporteros no habían sido invitados, seguidos de la amonestación por esa actitud.

Sin embargo, este poder no siempre se utilizaba para denunciar. Muchas veces se usaban las páginas periodísticas para ensalzar a alguien o aplaudirle por sus acciones o méritos.

"Nuestro amigo Nicasio F. de Latorre merece nuestra más cara manifestación de aprecio. Nicasio, como siempre activo, reunió el domingo (...) una cantidad (...) para hacer frente a los gastos de conducción del cuerpo de D. Giles". ${ }^{2}$

Las publicaciones constantes de distintas listas de suscripción, ya fueran para sostener un periódico o para ayudar económicamente a algún enfermo o a la familia de un fallecido, seguramente redundaban en aumentar el prestigio de quienes allí figuraban. Igualmente, aparecer en las páginas de los periódicos parecía ser un aliciente para la cooperación, como se puede entrever del siguiente pedido:

"Volvemos a repetir: esperamos de la filantropía de nuestra comunidad. Cada uno contribuya con lo que pueda o lo que quiera. Los nombres y la cantidad con que contribuya cada persona se publicarán sucesivamente en este periódico". ${ }^{73}$

Estas listas muchas veces eran iniciadas y recogidas por los mismos redactores de los periódicos, quienes, además, no sólo supervisaban el material que se editaba sino que también decidían qué se publicaba y qué no, introduciendo modificaciones a su antojo que podían afectar a los lectores, o hacerlos enojar:

71 La Perla, "Cosas", 25 de agosto de 1878, mayúsculas y en inglés en el original.

72 La Broma, "Gran surtido de sueltitos", 8 de febrero de 1878.

73 Ibídem, "Cumplamos con un deber", 4 de junio de 1880. 
“... por los enojos de cierto caballerito de la calle de Estados Unidos, que le fueron motivados porque los pícaros de los cajistas carnerearon sin razón el nombre del aludido de la lista [de un baile]". ${ }^{74}$

Como broma o seriamente, escribir en el periódico otorgaba capacidad de decidir sobre cómo se quería que se juzgara a la gente en el espacio público. Esto hacía que posiblemente no fuera buena idea pelearse con estos redactores, como ya se había demostrado en el caso mencionado de La Juventud, en que todo el periódico salió en defensa de su redactor.

Así, si los redactores y directores de los periódicos eran figuras que tenían influencia y poder en la vida de su comunidad debido a sus ideas y propuestas, se debía también a que poseían el control de un dispositivo que permitía denunciar y aplaudir conductas y personas en la contra esfera pública afroporteña, y por ende, con cierta posibilidad de figurar en la esfera pública hegemónica. No creemos que fuera esto último lo más importante a la hora de amenazar disciplinariamente, pero tampoco hay que omitirlo. La tiranía de la opinión pública de la que hablaba Quesada en $1883^{75}$ era también implacable en la comunidad afroporteña. De otro modo, estas amenazas no hubieran tenido sentido.

\section{Palabras finales}

Las ideas que circulaban en la Argentina decimonónica acerca de la importancia de la prensa escrita, de la tarea del periodista y de la importancia del "progreso" de los pueblos, aparecían también en las publicaciones de la comunidad afroporteña. La proliferación de periódicos que encontramos allí es impactante, sobre todo tratándose de una comunidad relativamente pequeña y en general con pocos recursos económicos. También son muy notables los números de suscriptores que estos periódicos decían tener, mostrando la importancia que éstos tenían para la comunidad y la efectividad de las formas de acercamiento a los lectores de sus escritos. Sin embargo, la comunidad afroporteña erigía una esfera pública que le era propia, paralela a la esfera pública burguesa a la que no podía acceder libremente, una esfera pública subalterna con potencial poder emancipatorio. Las formas que tomaba esta última eran similares a la esfera pública bur-

74 Ibídem, "Varillazos", 3 de septiembre de 1881, cursivas en el original.

75 Quesada: "El periodismo...". 
guesa, hecho que le permitía acoplarse a la opinión pública general y —en momentos puntuales - influir en ella, pero, sobre todo, llevaba a que esa comunidad se imbuyera de las "reglas apropiadas" de discusión pública.

Los periódicos afroporteños -empresas de algunos pocos convencidos de estar contribuyendo al bien común - se proponían como espacio abierto de discusión y como lugar de intercambio de información referente a la comunidad, a la que querían representar pero que veían "atrasada" y dividida. En ese contexto, los directores y redactores de los periódicos afroporteños luchaban por llevar adelante los cambios y peleaban por conservar su estatus de portavoces y guías de su comunidad. Los periódicos reflejaban esas luchas y formaban parte imprescindible de ellas, tomando la palabra para discutir y convencer de la idoneidad de sus ideas. Quienes estaban a cargo de las publicaciones ocupaban un lugar de poder muy singular. Se transformaron en agentes de cambio o intelectuales subalternos, haciendo acopio de poder y de prestigio. Imbuidos del apostolado del periodismo iniciaron cruzadas por la "regeneración" y confiaron en que los periódicos eran armas potentes para llevarla a cabo, siendo sus objetivos educar, civilizar, ilustrar, pero también ordenar y disciplinar. Como toda arma, el doble filo estaba en su poder de señalar públicamente a quienes se considerara que actuaban por fuera de las normas. Para ello, se constituyeron en un nodo que acumulaba y evaluaba información sobre la comunidad, que abría espacios de discusión y de reintegración identitaria pero que también censuraba y denunciaba a los "desviados", instituyéndose como un dispositivo panóptico que era manejado por unos pocos y que generalizaba el control y la disciplina a todos los niveles de la sociedad. En el interjuego establecido entre unos editoriales que fijaban las pautas ideológicas que debían seguirse y las denuncias que se hacían desde el resto de las secciones, los periódicos iban facilitando, en última instancia, la tarea del Estado en construcción de imponer su ideología y administrar a sus sujetos.

La prensa afroporteña de finales del siglo XIX constituyó, así, un conjunto significativo en un momento de crucial importancia en la consolidación del Estado nacional argentino. Como tal, coadyuvó a que los descendientes de esclavizados y esclavizadas que habitaban en Buenos Aires se formaran dentro de las pautas disciplinarias del Estado y de la imaginación que promovía la nación civilizada, una nación de ciudadanos con derechos, que estos periódicos pregonaban - y muchas veces lograban - defender. 